\title{
Third Ventricle Choroid Plexus Carcinoma
}

\author{
R.W. Broad and P.B.R. Allen
}

ABSTRACT: Benign and malignant tumors of the choroid plexus in infancy are extremely uncommon. Diagnosis and management of a malignant tumor is described and the literature survey of the problem is presented.

RÉSUMÉ: Les tumeurs bénignes et malignes du plexus choroïde dans l'enfance sont très rares. Nous avons décrit le diagnostic et le traitement d'une telle tumeur maligne, et une revue de la littérature à propos de ce sujet est presentée.

Can. J. Neurol. Sci. 1984; 11:461-465

The problems of choroid plexus tumors, third ventricular tumors in infants less than one year of age, and malignant lesions of the choroid plexus are all uncommon problems in both a general and pediatric neurosurgical practice. We describe a case of a third ventricular choroid plexus carcinoma occurring in infancy, supplementing our discussion with intraoperative photographs, and presenting various problems of this tumor and its management.

\section{CaSe Report}

A one day old infant boy was admitted in transfer to the University of Alberta Hospital in April 1983 presenting with enlarged head at birth.

Born of a 24 year old Caucasian mother, gravida I para $\mathrm{O}$, following a normal pregnancy of 40 weeks gestation, normal labor, and a spontaneous vaginal delivery. Apgar scores of 6 and 7 at one and five minutes respectively were noted, as was an enlarged head measuring $40 \mathrm{cms}$. (greater than the 90 th percentile). Length was at the 80 th and weight at the 45 th percentiles.

A maternal history of epilepsy was present, the mother previously having been on anticonvulsants, but discontinued six years prior with no recent seizures.

Examination of the infant revealed an enlarged head and full fontanelle without other abnormalities being present.

A preliminary diagnosis of hydrocephalus was made. A CT scan demonstrated enlarged lateral ventricles, a poorly visualized third ventricle, and normal sized fourth ventricle (figure 1). Contrast enhancement demonstrated a well defined, round, augmenting lesion filling the anterior half of the third ventricle and obstructing the interventricular foramen (figure 2). Ultrasonography of the head demonstrated a highly echogenic midline spherical mass measuring $3.1 \times 2.0 \times 2.9 \mathrm{cms}$ (figure 3 ); cerebral angiography demonstrated a very faint blush in the anterior aspect of the third ventricle with slight displacement of the septal veins and compression of the internal cerebral veins.

With the presentation of marked hydrocephalus, ventriculoperitoneal shunting was initially carried out. Following investigation as described above, a tentative diagnosis of a third ventricular choroid plexus papilloma was made, and a second procedure, a stereotactic tumor biopsy, was performed at three weeks of age. Although the biopsy material was limited, the histologic diagnosis was choroid plexus papilloma.

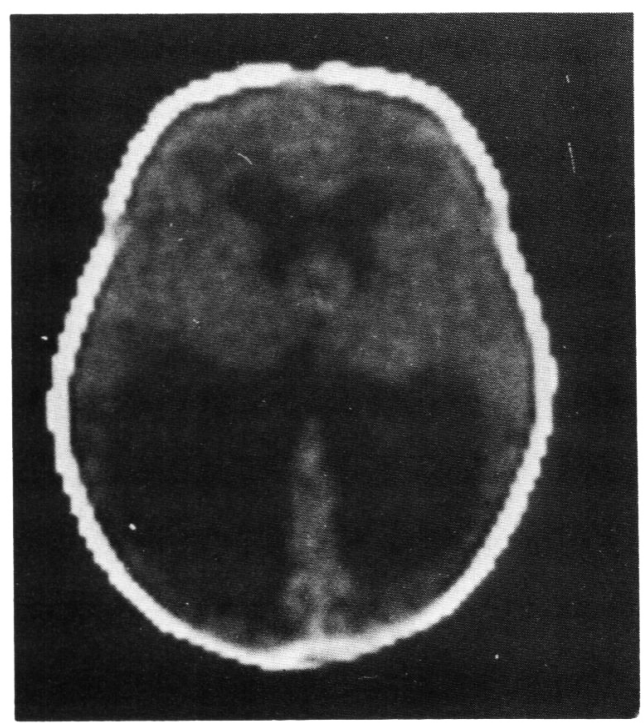

Figure 1-C.T. Scan showing massive hydrocephalus with evidence of a cystic mass in the region of the third ventricle.

As the infant was doing well, he was discharged and electively readmitted at $9 \frac{1}{2}$ weeks of age, when a definitive craniotomy and third ventriculostomy by an anterior corpus callosal section was carried out.

At operation, an extensive right frontal craniotomy was performed for exposure of the genu and rostrum of the corpus callosum (figure 4). This commisure was divided over a $2 \mathrm{~cm}$. section from the genu posteriorly, demonstrating that the corpus callosum had become attenuated to little more than a thin membrane. A large, firm, well circumscribed, papillated, pink/yellow tumor was encountered (figure 4), which filled the anterior half of the third ventricle and distorted the anatomy.

The tumor was carefully delivered through the third ventriculostomy, revealing its attachment to normal choroid plexus in the third ventricle by a narrow vascular stalk containing a single large feeding vessel. This artery was coagulated and the tumor removed in one piece. A Ziess operating microscope provided excellent visualization and demonstrated that total excision had been accomplished with satisfactory hemostasis (figure 4).

From the Division of Neurosurgery, University of Alberta, Edmonton, Alberta

Received January 30, 1984. Accepted August 1984.

Reprint requests to: Dr. P. Allen, 11 - 102 Clinical Sciences Building, University of Alberta, 11282 - 84 Avenue, Edmonton, Alberta, Canada T6G 2G3 
Postoperatively, the child had a rapid and uneventful recovery without seizures or fluid or electrolyte problems. Subsequently he has shown normal development over one year. Follow-up CT scan has returned to almost normal (figure 5).

With the study of further surgical biopsy material, a revised diagnosis of choroid plexus carcinoma was made. Despite this change, it was decided that because of total tumor removal, no further treatment (radiotherapy) be carried out. Close follow-up was arranged.

\section{Pathology}

The gross appearance of the tumor was a soft, lobulated pale pinkish-yellow mass. The total weight of the specimen was 18 gms. and it measured $7 \times 5 \times 3 \mathrm{cms}$ (figure 6). Its papillary nature was seen on cut surface.

Microscopically, most of the tumor consisted of areas characteristic of a choroid plexus neoplasm, with a papillary architecture consisting of a cuboidal to low columnar epithelium covering

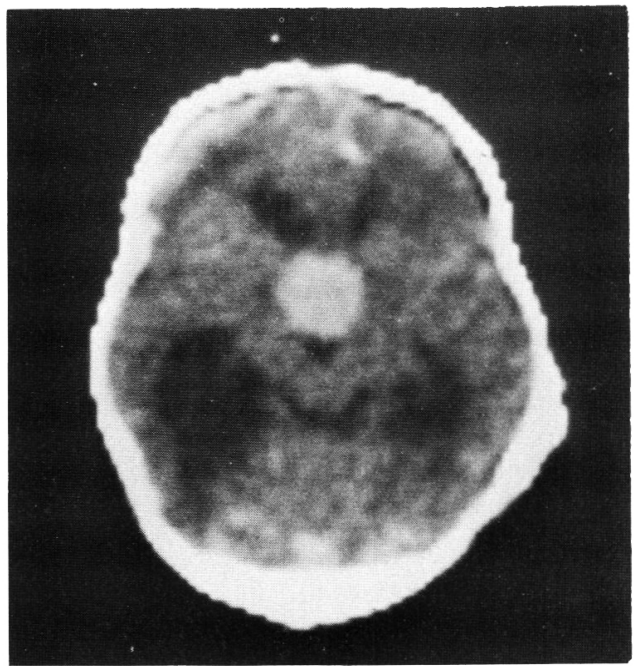

Figure 2 - Contrast-enhanced C.T. Scan demonstrating lesion within the third ventricle.

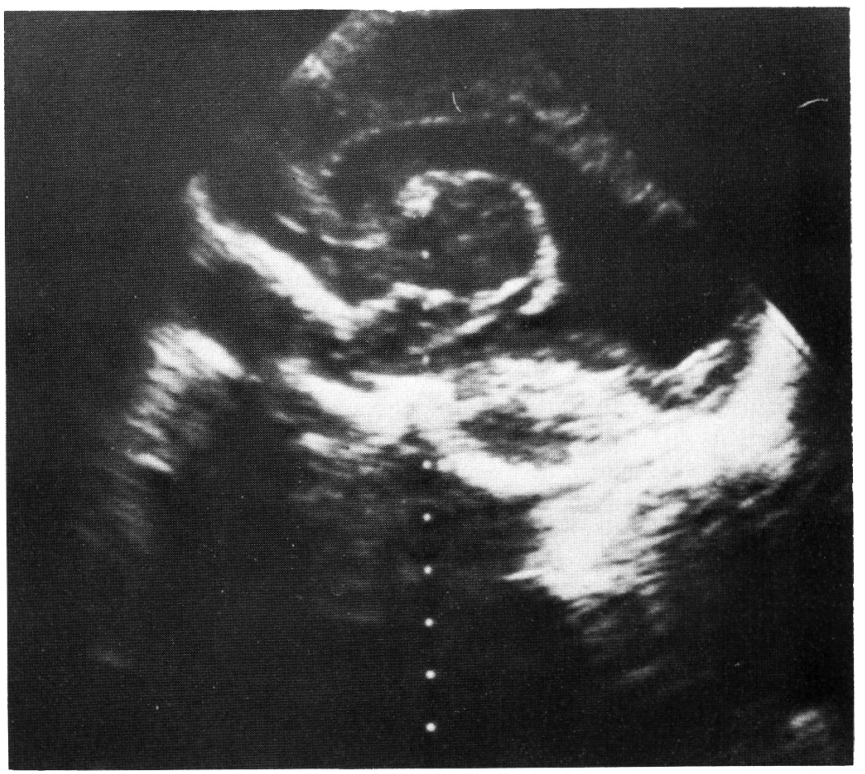

Figure 3 - Ultrasound images of a solid mass in the third ventricle. a fibrovascular stroma (figure 7). However, other areas exhibited epithelial stratification with piling up of nuclei and the presence of occasional mitotic figures (figure 7), nuclear irregularities, and hyperchromatism. These findings provided the basis for the diagnosis of choroid plexus carcinoma (Lewis, 1967; Russell \& Rubinstein, 1971; Burger \& Vogel, 1983; Rubinstein, 1983).

\section{Discussion}

Choroid plexus carcinoma in the third ventricle in infancy is an extreme rare occurrence. Choroid plexus tumors comprise $0.5 \%$ of all brain tumors at all ages (Davis \& Cushing, 1925; Stanley, 1968; Zulch, 1957). The incidence in childhood is greater than in adult life, being $2.3 \%$ in those under 17 years of age (Thompson et al., 1973), 3.9\% in those under 12 (Matson \& Crofton, 1960), 9\% in those under 2 (Matson \& Crofton, 1960), and $14 \%$ in infants less than one year of age (Raimondi and Tomita, 1983; Sato et al., 1975).

Localization of choroid plexus tumors for all ages shows that the fourth ventricle, lateral ventricle and third ventricle are the common sites being a frequency of $45.5 \%, 40.7 \%$ and $10.4 \%$ respectively (Fortuna et al., 1979). Reported cases have been described occurring at the cerebellopontine angle, intracerebrally, and in the spinal subarachnoid space (Laurence, 1974), as described in a recent review analyzing 60 cases of third ventricular choroid plexus tumors in the literature with 43 of these cases examined in detail (Fortuna et al., 1979). In infancy the localization of choroid plexus tumors is much different. Combining Sato's and Raimondi's series of tumors presenting in infancy, only 4 cases of choroid plexus tumors occurred in the third ventricle with the remainder being in the lateral ventricles (Sato et al., 1975; Raimondi and Tomita, 1983). In the series of third ventricular choroid plexus papillomas, it was noted that $30 \%$ occurred in childhood (Fortuna et al., 1979).

From the perspective of the differential diagnosis of intraventricular tumors occurring in the third ventricle during infancy,

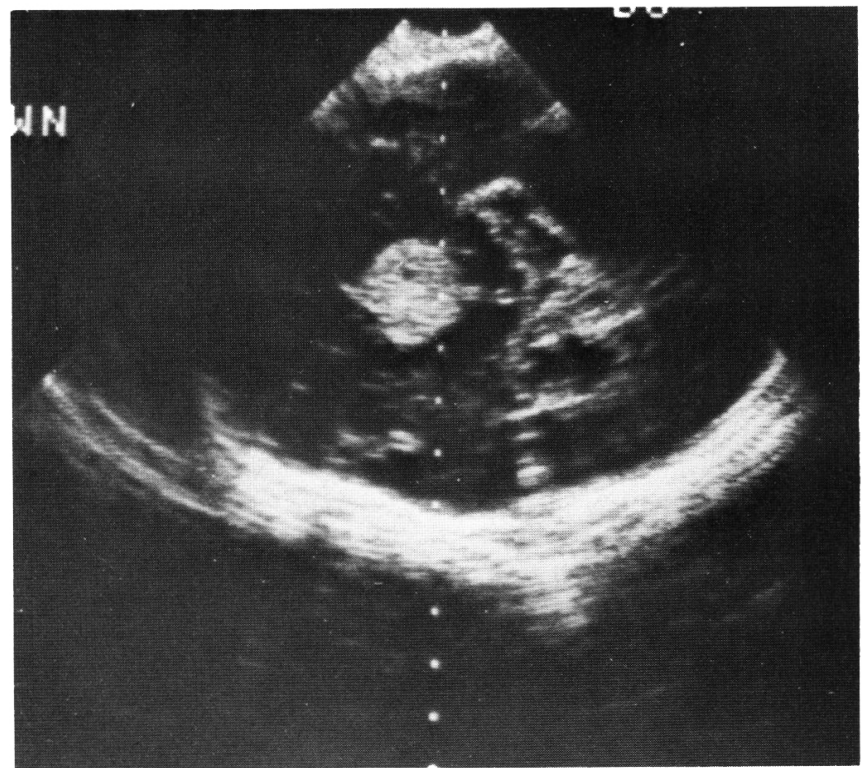



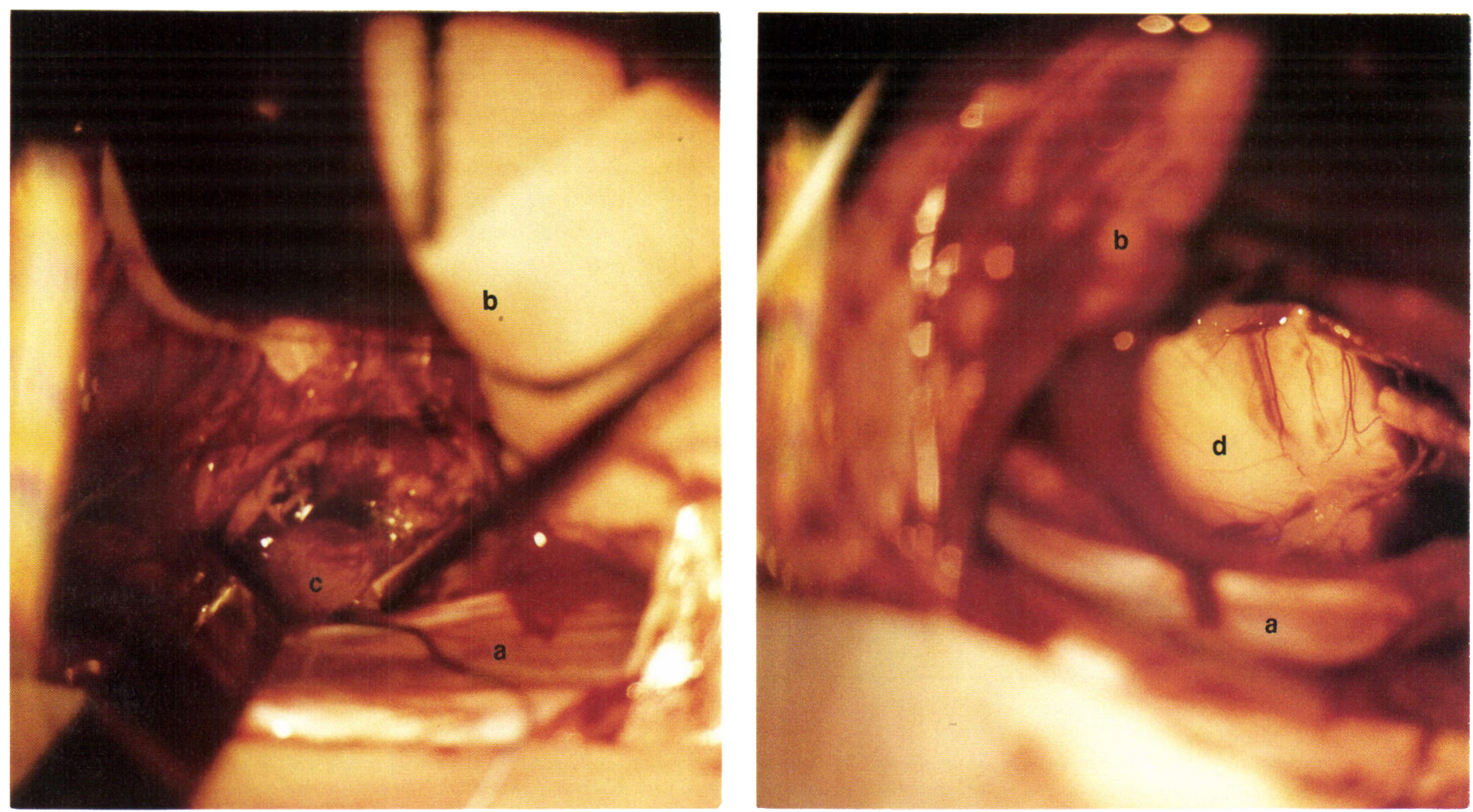

Figure 4-Intraoperative photographs illustrating: (a) Falx cerebri, (b) Right anterior parietal lobe retracted laterally, (c) Tumor presenting through a thinned corpus callosum, (d) The floor of the third ventricle after the complete removal of the tumor.

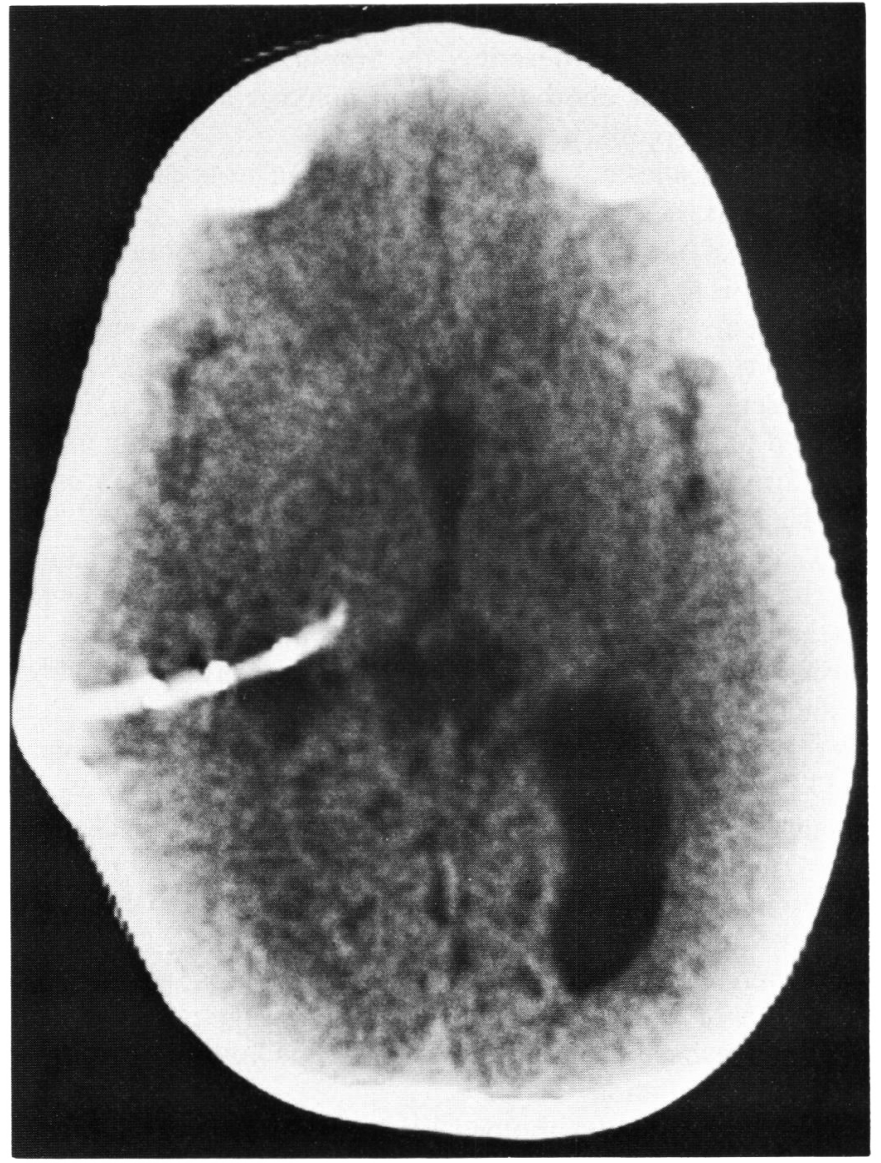

Figure $5-$ C.T. Scan 9 months following removal of tumor. The right lateral ventricle is collapsed, and the posterior horn of left lateral ventricle remains enlarged.

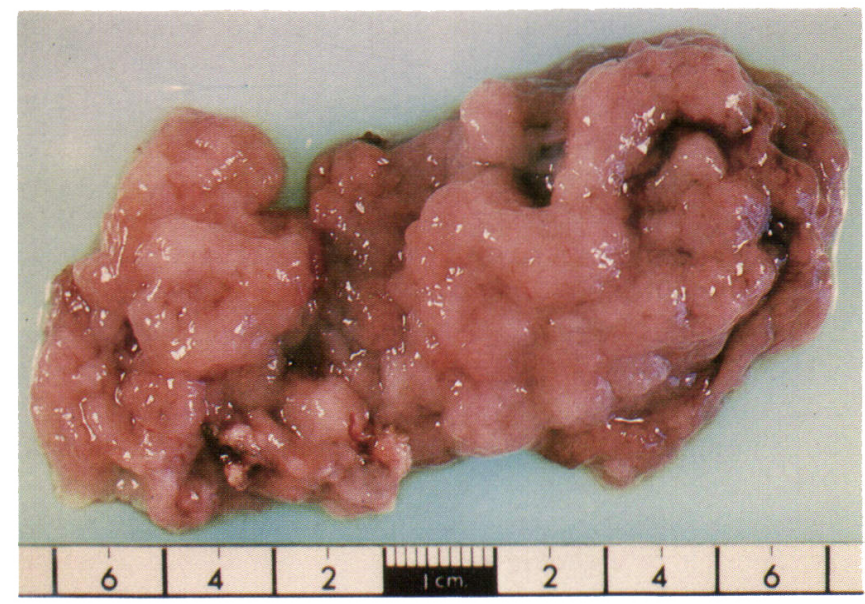

Figure 6-Multilobular, soft tumor mass removed from within the third ventricle. Vascular pedicle, and point of adherence to ventricle wall evident at left, inferior margin. 

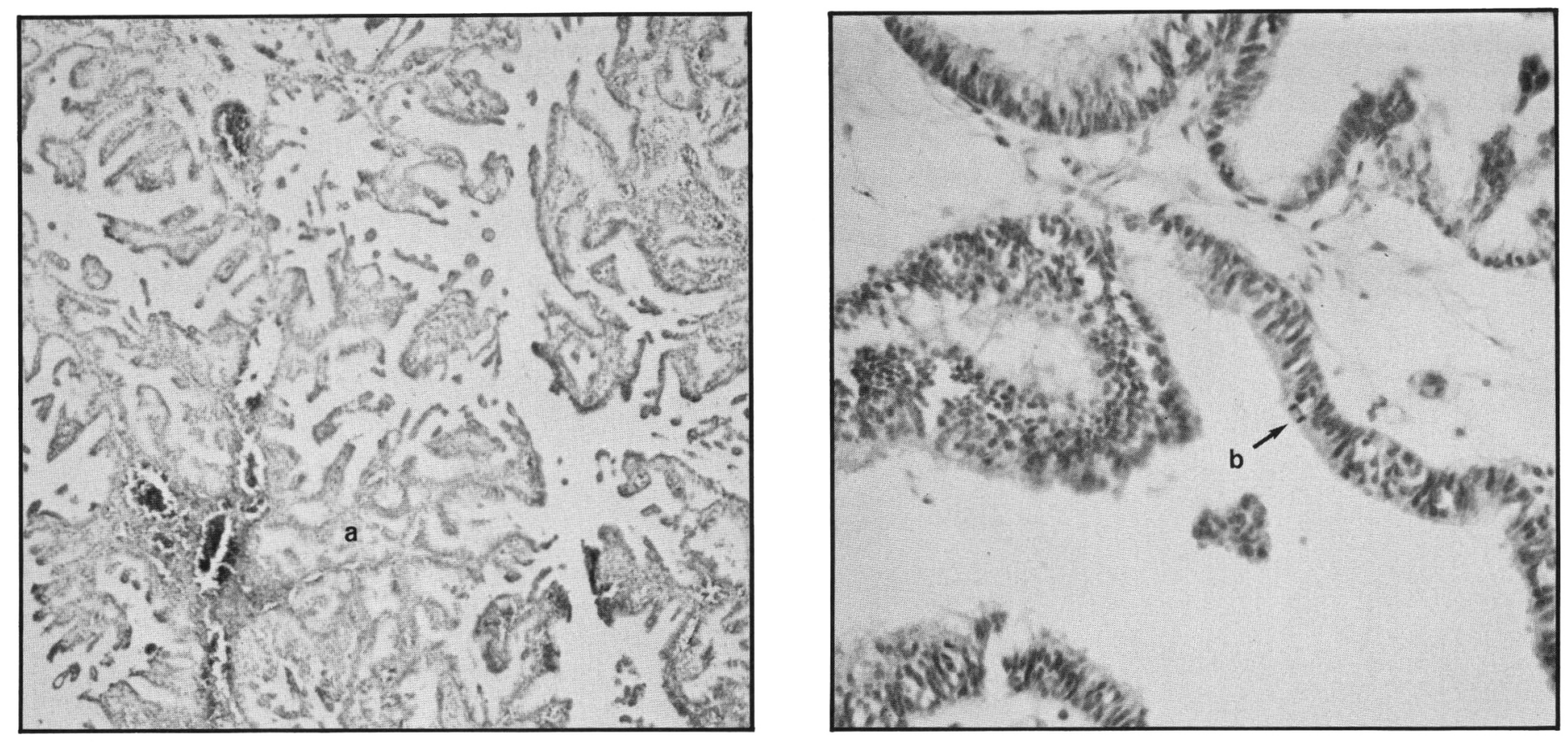

Figure 7 - Photomicrographs of sections through the tumor showing: (a) dominant papillary architecture of branched processes of fibrovascular stroma covered by cuboidal to low columnar epithelium and $(b)$ an area of epithelial stratification with piling up of nuclei and the presence of occasional mitotic figures.

$80 \%$ were choroid plexus tumors; the only other diagnoses reported are astrocytoma, malignant teratoma, and primitive neuroectodermal tumor (Sato, 1979; Raimondi, 1983).

The incidence of malignancy is not clearly defined when describing neoplasms of the choroid plexus. In the literature review of third ventricular choroid plexus tumors (Fortuna et al., 1979), $21 \%$ were described as malignant, although the criteria were not discussed. The incidence is probably much lower if criteria of epithelial stratification with piling of nuclei and increasing mitotic figures are adhered to. In Fortuna's review, no cases of malignant choroid plexus neoplasms are described as occurring in infancy and similarly, no malignant cases were encountered in Raimondi and Sato's series of tumors of the third ventricle. As this is an unique case of a third ventricular choroid plexus carcinoma, it is reasonable to give careful consideration to the criteria of malignancy in lesions of this tissue. Several criteria were recently reiterated by Carpenter et al. (1982), based upon those of Zulch (1956, 1957): 1) infiltration and destruction;2) abundant cellularity; 3) pleomorphic nuclei and variation in cellular type; 4) mitoses; 5) vascular proliferation; 6) necrosis, 7) loss of boundaries between stroma and parenchyma.

Though valid and complete, these criteria have not been sought out by all observers before considering malignancy (Burger and Vogel, 1983; Lewis, 1967; Russell \& Rubinstein, 1971; Turner \& Simon, 1937), and as with other tissues and organs, an acknowledgement between invasive carcinoma and carcinoma in situ should be given. Review of our generous specimen by outside authorities have supported our diagnosis of choroid plexus carcinoma (Rubinstein, personal communication).

Historically, the landmarks of the surgical management of choroid plexus tumors include the first reported surgical removal (unsuccessful) in 1902 by Bielschowsky and Unger, and the first successful surgical removal in 1919 by Perthes. Dandy provided the pioneer work on localization of third ventricular tumors and described the transcallosal approach to that area $(1922,1934)$. Masson described the first successful removal of a third ventricular choroid plexus papilloma in 1934, using a transfrontal approach.

The transcallosal approach was carried out in our case because it provided the best access to a very large tumor, and recent reviews of the choice of approaches (transfrontal versus transcallosal) point out that no significant psychological problems occur with a limited anterior callosal section, better visualization results, and the incidence of postoperative epilepsy is less (Benes, 1982; Jeeves et al., 1979; Winston et al., 1979). It should be emphasized that care must be taken not to damage the fornices to prevent damage to the memory apparatus in both approaches (Jooma and Grant, 1983).

The surgical mortality remains high for this lesion mainly because of the restricted exposure, which makes dealing with bleeding from the tumor very difficult, and the possibility of losing control of the vascular pedicle to the tumor a real possibility. Raimondi and Tomita (1983) described one intraoperative death in a series of three third ventricular choroid plexus papillomas, and Fortuna et al. (1979) reported a total mortality of $48 \%$ in surgically approached third ventricular choroid plexus papillomas. This rate dropped to a still very high $23 \%$ with total resection, although most of the included series occurred prior to the use of the operating microscope.

Because of the limited numbers of these cases, no information is available about the results of nonsurgical or limited surgical management such as shunting without excision and interstitial radiation.

Despite the histopathology being that of a choroid plexus carcinoma, the child has been managed with total excision and 
no radiation therapy. In our experience, and as cautioned by Raimondi, poor subsequent development may occur in children receiving supratentorial radiation. Fessard (1968) saw normal development in only five out of 62 cases with radiotherapy in early childhood and of these five normals, all had posterior fossa lesions. Similarly, Farwell et al. (1978) found only 3 of 17 infants developed normally following radiation to the whole brain. With CT scanning, early recurrences can be detected and radiation considered at that time. Whether this approach alters with the development of newer techniques in radiotherapy such as the use of sensitizers, interstitial radiation, and "radiation knives", remains to be seen.

\section{ACKNOWLEDGEMENTS}

The authors express their appreciation to Dr. B.W. Mielke, Department of Pathology, University of Alberta, and Dr. L.J. Rubinstein, Professor of Pathology, Charlottesville, Virginia, for their review of the pathological material. To Mrs. Arlene MacLean for preparation of the manuscript.

\section{REFERENCES}

Arnstein LH, Boldrey E and Naffsiger HL (1951) A case report and survey of brain tumors during the neonatal period. J. Neurosurg. 8: 315-319.

Arseni C, Constantinescu A, Danaila L and Istrate C (1974) The choroid plexus papillomas. Neurochirurgia 17: 121-129.

Bailey P, Buchanan DN and Bucy PC (1939) Intracranial tumors of infancy and childhood. University of Chicago Press, Chicago.

Benes V (1982) Sequelae of transcallosal surgery. Child's Brain 9: 69-72.

Bielschowky M and Unger E (1902) Zur Kenntnis der primaren Epithelgeschwulste der Adergeflechte des Gehirns. Arch. klin. Chir. 81: 61-82.

Bleyer A and Siebert WJ (1936) A papilloma of the choroid plexus in an infant. J. Pediat. 8: 193-196.

Bohm E and Atrang R (1961) Choroid plexus papillomas. J. Neurosurg. 18: 493-500.

Burger PC and Vogel FS (1983) Surgical Pathology of the Nervous System and its Coverings, Second Edition, pp. 320-326. J. Wiley \& Sons, Toronto.

Carpenter DB, Michelsen WJ and Hays AP (1982) Carcinoma of the Choroid Plexus. J. Neurosurg. 56: 722-727.

Cuatico G and Castan P (1962) Choroid plexus papilloma of third ventricle. J. Neurosurg. 19: 1085-1087.

Cushing $\cdot H$ (1932) Intracranial tumors. Notes upon a series of two thousand verified cases with surgical mortality percentages pertaining thereto. Thomas, Springfield.

Dandy WE (1922) Diagnosis, localization and removal of tumors of the third ventricle. Bull. Johns Hopkins Hospital 33: 188-189.

Dandy WE (1933) Benign tumours in the third ventricle of the brain. Diagnosis and treatment, p. 171. Thomas, Springfield.

Davis LE and Cushing H (1925) Papillomas of the choroid plexus with a report of six cases. Arch. Neurol. Psychiat. 13: 681-710.

Drucker GA (1939) Papillary tumor of the choroid plexus in a newborn infant. Arch. Path. 28: 390-395.

Farwell JR, Dohrmann EJ and Flannery JT (1978) Intracranial neoplasms in infants. Arch. Neurol. Chicago 3: 533-537.

Fessard C (1968) Cerebral tumors is infancy. 66 clinico-anatomical case studies. Am. J. Dis. Child 115: 302-398.

Fortuna A, Celli P, Ferrante L and Turano C (1979) A review of papillomas of the third ventricle. J. Neurosurg. Sci. 23: 61-72.

Gillis DA and Diprofio CRF (1956) Papillary tumors of the choroid plexus. Can. Med. Ass. J. 74: 361-363.

Greene RC (1951) Extraventricular and intra-cerebellar papilloma of the choroid plexus. J. Neuropath. exp. Neurol. 10: 204-207.
Hawkins JC (1980) Treatment of choroid plexus papillomas in children. A brief analysis of twenty years' experience. Neurosurgery 6: 380-384.

Herren RY (1941) Papilloma of the choroid plexus. Archs. Surg., Chicago 42: 758-774.

Jeeves MA, Simpson DA and Geffen G (1979) Functional consequences of the transcallosal removal of intraventricular tumors. J. Neurol. Neurosurg. Psychiat. 42: 134-142.

Jooma R and Grant DN (1983) Third Ventricle Choroid plexus papillomas. Child's Brain 10: 242-250.

Laurence KM, Hoare RD and Till K (1961) The diagnosis of the choroid plexus papilloma of the lateral ventricle. Brain 84: 628-641.

Laurence KM (1974) The Biology of choroid plexus papilloma and carcinoma of the lateral ventricle. In: Handbook of Clinical Neurology, Vol. 17: 555-594, Elsevier, New York.

Lewis P (1967) Carcinoma of the choroid plexus. Brain 90: 177-186.

Masson CB (1934) Complete removal of two tumors of the third ventricle with complete recovery. Archs. Surg. 38: 527-537.

Matson DD (1953) Hydrocephalus in a premature infant caused by papilloma of the choroid plexus with report of surgical treatment. J. Neurosurg. 10: 416-420.

Matson DD and Crofton FDL (1960) Papilloma of the choroid plexus in childhood. J. Neurosurg. 17: 1002-1027.

Matson DD (1964) Intracranial tumors of the first two years of life. West. J. Surg. Obstet. Gynec. 72: 117-122.

Matson DD (1969) Neurosurgery of infancy and childhood, Second ed., p. 934. Thomas, Springfield.

Milhorat TH and Baldwin M (1966) A technique for surgical exposure of the cerebral midline: experimental transcallosal microdissection. J. Neurosurg. 24: 687-691.

Milhorat TH, Hammoch MK, Davis DA and Fensternacher JD (1976) Choroid plexus papilloma. Proof of cerebrospinal fluid overproduction. Child's Brain 2: 273-289.

Nassar SI and Mount L (1968) Papillomas of the choroid plexus. J. Neurosurg. 29: 73-77.

Perthes GC (1919) Gluckliche Entfernung eines Tumors des Plexus Choriodeus an dem Seitenventrikel des Cerebrum. Munch. Med. Wschr. 66: 677-678.

Raimondi AJ and Gutierrez FA (1975) Diagnosis and surgical treatment of choroid plexus papilloma. Child's Brain 1: 81-115.

Raimondi AJ and Tomita T (1983) Brain tumors during the First year of life. Child's Brain 10: 193-207.

Rovit R, Schechter MM and Chodroff $\mathrm{P}(1970)$ Choroid plexus papillomas: observations on radiographic diagnosis. Am. J. Roentg. 100: 608-617.

Russell DS and Rubinstein LJ (1971) Pathology of tumors of the nervous system, pp. 220-224. Arnold, London.

Rubinstein LJ (1983) Personal communication.

Sato O, Tamura A and Sano K (1975) Brain tumors of early infants. Child's Brain 1: 121-125.

Stanley P (1968) Papillomas of the choroid plexus. Brit. J. Radiol. 41: 848-857.

Thompson SR, Harwood-Nash CR and Fitz CR (1973) The Neuroradiology of childhood choroid plexus neoplasma. Amer. J. Roent. Rad. Ther. Nuc. Med. 118: 116-231.

Tomasello F, Albanese V and Bernini FP (1981) Choroid plexus papilloma of the third ventricle. Surg. Neurol. 16: 69-71.

Turner OA and Simon MA (1937) Malignant papillomas of the choroid plexus: Report of two cases with a review of the literature. Amer. J. Cancer 30: 289-297.

Van Wagenen WP (1930) Papillomas of choroid plexus; report of two cases, one with removal of tumor at operation and one with 'seeding' of tumor in ventricular system. Arch. Surg., Chicago 20: 199-231.

Wilkins $\mathrm{H}$ and Rutledge BJ (1961) Papillomas of the choroid plexus. J. Neurosurg. 18: 14-18.

Winston KR, Cavazzuti V and Arkins T (1979) Absence of neurological and behavioural abnormalities after anterior transcallosal operation for third ventricular lesions. Neurosurgery $4: 386-393$.

Zulch KJ (1956) Biologie und pathologie der Hirngeschwulste, in Zulch K.J., Christensen E. (eds.) Pathologische Anatomie der Raumbeengenden Intrakraniellen Prozesse. Handbuch der Neurochirurgie Vol. 3. Springer, Verlag, 1-702.

Zulch KJ (1957) Brain tumors: their biology and pathology. Springer, New York. 